\title{
Prevalence of Hypertension and Its Associated Factors among Adults in Selected Areas of Bangladesh: A Community Based Cross-sectional Study
}

\author{
Md. Nahian Rahman ${ }^{1}$, Syeda Saima Alam², Shaidaton Nisha ${ }^{1}$, Faroque Md Mohsin ${ }^{3}$, Mahmudul Mannan ${ }^{4}$, Md. \\ Mahedi Hasan ${ }^{5}$, Md. Mahbubur Rahman ${ }^{1}$, Smita Roy Tory ${ }^{1}$, Sabrina Rahman ${ }^{6}$, Abu Zobayed ${ }^{7}$, Mosharop \\ Hossain $^{8}$, Jakaria Al Mamun ${ }^{1}$, Omar Faruk ${ }^{1}$, Sumaiya Jahan Dina ${ }^{1} \&$ Khaleda Islam ${ }^{9}$ \\ ${ }^{1} \mathrm{MSc}$, Institute of Nutrition and Food Science, University of Dhaka, Bangladesh \\ ${ }^{2}$ Lecturer, Department of Food Technology and Nutrition Science, Noakhali Science and Technology University, \\ Bangladesh \\ ${ }^{3}$ Medical Officer, Directorate General of Health Services, Ministry of Health and Family Welfare, Bangladesh \\ ${ }^{4}$ MSc, Faculty of Health Science, McMaster University, Canada \\ ${ }^{5}$ BSc (Institute of Nutrition and Food Science, Dhaka University, Bangladesh), MPH (Northern University), \\ Bangladesh \\ ${ }^{6}$ BSc (Institute of Nutrition and Food Science, Dhaka University), MPH (North South University), Bangladesh \\ ${ }^{7}$ M. Pharm, Department of Clinical Pharmacy \& Pharmacology, Faculty of Pharmacy, University of Dhaka, \\ Bangladesh \\ ${ }^{8}$ BSc, Department of Statistics, Faculty of Science, University of Dhaka, Bangladesh \\ ${ }^{9}$ Professor, Institute of Nutrition and Food Science, University of Dhaka, Bangladesh \\ Correspondence: Md. Nahian Rahman, Institute of Nutrition and Food Science, University of Dhaka, Bangladesh. \\ Tel: 880-167-464-5407. E-mail: rahman_nahian@yahoo.com
}

Received: March 24, 2021

Accepted: December 5, $2021 \quad$ Online Published: December 8, 2021

doi:10.5539/jfr.v10n6p56

URL: https://doi.org/10.5539/jfr.v10n6p56

\begin{abstract}
Background: Hypertension is a silent killer and an overwhelming global public health challenge. This study aimed to determine the prevalence and associated factors of hypertension among adults in Bangladesh.

Methods: A community-based cross-sectional study design was conducted among 400 adults who lived in Dhaka, Mymensing, Sylhet and Khulna District. Data were collected using a structured questionnaire that is adapted from the WHO Stepwise approach. Data was analyzed by SPSS version 25. Descriptive statistics and bivariate logistic regression analysis were conducted and statistical significance was declared at a p-value $\leq 0.05$.

Results: This study identified a high prevalence of hypertension in the study area and it was $39.75 \%$. Among the male the prevalence was $23.5 \%$ and the prevalence was $16.5 \%$ among female. In this study hypertension was significantly associated with the age group 51-65 years ( $\mathrm{OR}=1.02$; $\mathrm{CI}$ 0.557-1.862), ever smoking $(\mathrm{OR}=2.59$; CI 1.718-3.917) consume less fruits (OR=3.125; CI 0.839-11.632) and vegetable (OR=2.25; CI 1.364-3.725), physically inactive $(\mathrm{OR}=1.48$; CI $0.973-2.252)$ overweight $(\mathrm{OR}=7.98$; $\mathrm{CI}$ 4.612-13.793) and had diabetes mellitus (0R=2.38; CI 1.213-4.659).

Conclusion: The prevalence of hypertension was considerably higher in this study area. Hence, the health care system needs to establish strategies to improve the diagnostic and screening services. Community-level intervention and regular assessment, screening, and diagnosis of behavioral, socio-demographic, and physiological risk factors, screening, should be institutionalized to address the occult burden of hypertension.
\end{abstract}

Keywords: hypertension, adults, Bangladesh cross-sectional study, Prevalence, associated factors, Bangladesh

\section{Introduction}

Hypertension is an important concern in public health (Erem, Hacihasanoglu, Kocak, Deger \& Topbas, 2009; Abebe, Berhane, Worku \& Getachew, 2015; Mishra \& Kumar, 2011; Ahmed et al., 2014). It is associated with 
life-threatening complications such as cerebrovascular accidents, coronary artery disease, congestive heart failure, peripheral arterial diseases and renal failure (Collaboration, 2003; Giles, Materson, Cohn \& Kostis, 2009). In 2015 it was reported that approximately 1.13 billion adults had hypertension around the world (Zhou et al., 2017) and it contributed nearly 211.8 million disability adjusted life years (DALYS) (Gakidou et al., 2016). Globally, almost one billion adults had hypertension in 2000 and this is predicted to increase to 1.56 billion by 2025. The prevalence of hypertension is rapidly rising in developing countries and is a major leading cause of disability and death (Chockalingam, Campbell \& Fodor, 2006; Kiber, Wube, Temesgen, Woyraw \& Belay, 2019). Limited data regarding the trends of prevalence of hypertension stated that it has increased in developing countries in recent years while it persisted stable or declined in developed countries (Kearney, Whelton, Reynolds, Whelton \& He, 2004). Currently 23 countries are responsible for about $80.0 \%$ of the total burden of chronic diseases mortality in developing countries. Among these countries, Bangladesh has the ninth highest rate of age-standardized rates of deaths due to chronic illnesses, mostly due to diabetes and cardiovascular diseases (Ahmed et al., 2014; Abegunde, Mathers, Adam, Ortegon \& Strong, 2007). Bangladesh is in the middle of an epidemiologic transition. This country is beginning to witness a shift in the major causes of death from nutritional deficiencies and infectious diseases to those due to chronic diseases (Ahmed et al., 2014). Factors attributed to the increased prevalence of hypertension are the growth of the population, aging of the population, and behavioral risk factors, such as poor diet, smoking, physical activity, harmful use of alcohol, and overweight or obesity (Organization WH, others, 2013; Islam, Zaman, Haq, Ahmed \& Al-Quadir, 2018). However, there is limited study in Bangladesh, a country where the highest mortality rate is occurred due to chronic illness. Hence we conducted a study to determine the prevalence, and identify factors associated with hypertension among adults in selected areas of Bangladesh.

\section{Methods}

\subsection{Study Settings and Participants}

This study was conducted among 400 adults who lived in Dhaka, Mymensing, Sylhet and Khulna District for more than six months before the survey. Multistage sampling technique was used; for selecting the primary sampling units, four districts were randomly selected from the total of 8 districts. Sample size was equally distributed to each of the selected districts. Finally, systematic random sampling technique was employed to select households for data collection. From the selected households, eligible adults were identified, and if there were more than one adult were found in a household, and then one was randomly selected.

\subsection{Data Collection and Measurement}

The WHO STEPS instrument was used to collect the data which contains three components of risk factor measurement which are demographic and behavioral measurement, physical measurement, and biochemical measurements (STEPS WHO, 2002). The tool was then translated to Bengali. To balance gender composition for the interview, data were collected on weekends and on working days in the afternoon during which time eligible adults were expected to be at home. Before the actual data collection was started, a pre-test was conducted to check for the validity of the instruments and then necessary modifications were made.

Standard procedures and the calibrated instruments were used to conduct anthropometric measurement. Weight and height was measured using digital scale and stadiometer respectively. For measuring blood pressure (BP) digital BP apparatus was used. BP was recorded three times, three to five minutes apart from the left arm while the person was sitting and the arm was resting on a flat surface and The average of the last two measures was used to identify elevated BP. Digital glucometers were used for biochemical testing to measure capillary blood sugar after subject was asked about the time lapse from the last meal.

\subsection{Operational Definition}

Digital glucometers were used for biochemical testing according to WHO and International Diabetic Association (IDA) define diabetes as fasting blood suger $\geq 26 \mathrm{mg} / \mathrm{dl}$ or random blood sugar $\geq 200 \mathrm{mg} / \mathrm{dl}$; hypertension: persistently elevated blood pressure, $\mathrm{SBP} \geq 140 \mathrm{mmHg}$ or $\mathrm{DBP} \geq 90 \mathrm{mmHg}$, or reported uses of antihypertensive medication (Angaw, Dadi \& Alene, 2015; Awoke, Awoke, Alemu, Megabiaw, 2012; Demisse et al., 2017). In this study, ever smoking was defined as smoking cigarette at least one in lifetime. Current alcohol consumption was defined as intake of alcohol during the last 30 days. Body mass index was used to classify nutritional status of study population. Asian criteria-based BMI was used as follows: underweight: BMI $<18.5 \mathrm{~kg} / \mathrm{m} 2$, normal-weight: 18.5-22.9 kg/m2, overweight: $23.0-27.5 \mathrm{~kg} / \mathrm{m} 2$, and obese: $>27.5 \mathrm{~kg} / \mathrm{m} 2$ (Who, 2004). Physical activity was measured as total global physical activity: inactive: $<600$ MET-minute and active: $\geq 600$ MET-minute (Roba, Beyene, Mengesha \& Ayele, 2019). 


\subsection{Statistical Analysis}

The data were checked and entered in to SPSS 23.0 statistical software. To identify association between hypertension and its associated factors a regression model was used. Statistical tests were considered significant at $\mathrm{P}$-value $<0.05$.

\section{Results}

A total 400 respondents participated in the study. The mean age of participants was $43.43 \pm 19.82$ years. Majority $(58.75 \%)$ of the study participants were male. Approximately Two thirds of the respondents $(68.5 \%)$ were. $35 \%$ of the study participants were farmer whereas $22 \%$ were housewife (Table 1 ).

Table 1. Sociodemographic characteristics of adults in selected areas of Bangladesh

\begin{tabular}{lll}
\hline Characteristics & Frequency & Percent \\
\hline Sex & & \\
Male & 235 & 58.75 \\
Female & 165 & 41.25 \\
Age & & \\
$18-35$ & 115 & 28.75 \\
$36-50$ & 126 & 31.5 \\
$51-65$ & 74 & 18.5 \\
66-93 & 85 & 21.25 \\
Education & & \\
HSC and above & 101 & 13.5 \\
SSC & 119 & 29.75 \\
Primary & 154 & 38.5 \\
No education & 73 & 18.25 \\
Marital status & & \\
Married & 274 & 68.5 \\
Single & 86 & 21.5 \\
Divorced & 23 & 5.75 \\
Widowed & 17 & 4.25 \\
Districts & & \\
Dhaka & 100 & 25 \\
Mymensing & 100 & 25 \\
Sylhet & 100 & 25 \\
Khulna & 100 & 25 \\
Occupation & & \\
Housewife & 88 & 22 \\
Farmer & 140 & 35 \\
Private Job & 72 & 18 \\
Unemployed & 100 & 25 \\
\hline & &
\end{tabular}

\subsection{Prevalence of Hypertension}

The mean Systolic blood pressure (SBP) was $126.48 \pm 18.11 \mathrm{mmHg}$ in men and $122.07 \pm 14.61 \mathrm{mmHg}$ in women. However, there was no statistically significant difference in systolic blood pressure between male and female participants $(\mathrm{t}=1.03$ and $\mathrm{P}<0.3275$ ) (Figure 1). The mean Diastolic blood pressure (DBP) was $82.34 \pm 13.42$ $\mathrm{mmHg}$ in men and $76.0 \pm 11.24 \mathrm{mmHg}$ in women with statistically significant difference $(\mathrm{t}=2.58$ and $\mathrm{P}<0.0001)$ (Figure 2). Both SBP and DBP were significantly increased with age (SBP, F=12.10, P<0.001; DBP, F=7.67, $\mathrm{P}<0.001$ ) (Figures 1 and 2). Using the 2017 ACC/AHA guidelines, the prevalence of hypertension was $39.75 \%$ (Table-3). Majority (61.5\%) of adults were not aware of their elevated blood pressure status. 


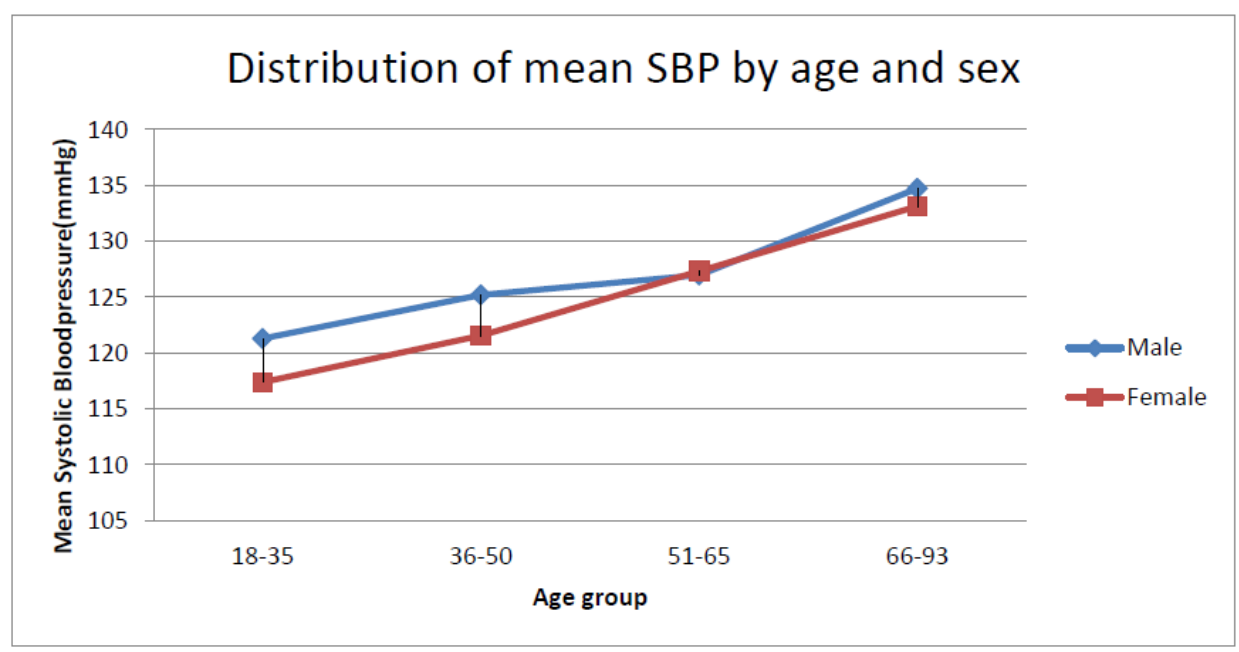

Figure 1. Distribution of mean SBP by age and sex

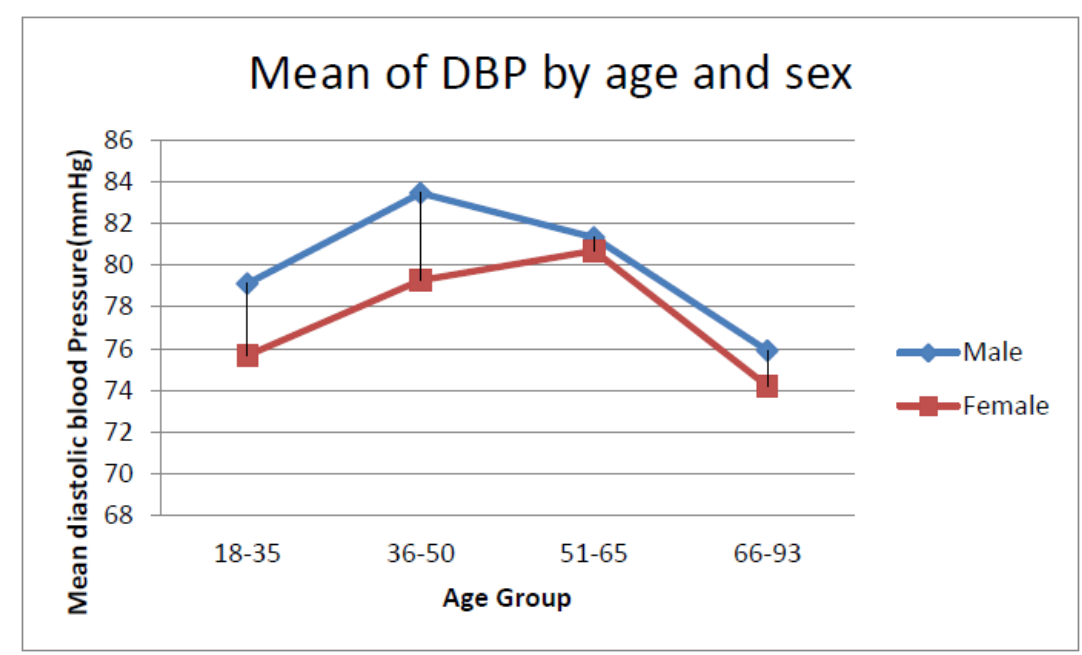

Figure 2. Distribution of mean DBP by age and sex

Table 3. Distribution of Hypertensive patients

\begin{tabular}{lllll}
\hline Blood Pressure & $\%(\mathrm{SBP})$ & $\mathrm{n}(\mathrm{SBP})$ & $\%(\mathrm{DBP})$ & $\mathrm{n}(\mathrm{DBP})$ \\
\hline Normal BP & 52.5 & 210 & 52.5 & 210 \\
Elevated BP & 7.75 & 31 & 7.75 & 31 \\
Stage-1 Hypertension & 15 & 60 & 6.5 & 26 \\
Stage-2 Hypertension & 24.75 & 99 & 33.25 & 133 \\
Total & 100 & 400 & 100 & 400 \\
\hline
\end{tabular}

\subsection{Factors Associated with Hypertension}

A logistic regression models were used to identify the factors associated with hypertension. 
Table 4. Factors affecting hypertension

\begin{tabular}{|c|c|c|c|c|c|}
\hline \multirow{3}{*}{$\begin{array}{l}\text { Variables } \\
\text { Sex }\end{array}$} & \multirow{2}{*}{\multicolumn{2}{|c|}{$\begin{array}{l}\text { Hypertension } \\
\text { Yes (N\&\%) }\end{array}$}} & \multirow{2}{*}{\multicolumn{2}{|c|}{$\begin{array}{l}\text { Hypertension } \\
\text { No }(N \& \%)\end{array}$}} & \multirow[t]{2}{*}{ OR(ODD Ratio) CI (95\%) } \\
\hline & & & & & \\
\hline & & & & & \\
\hline Male & 93 & 39.57 & 142 & 60.43 & 1 \\
\hline Female & 66 & 40 & 99 & 60 & $1.02(0.677-1.528)$ \\
\hline \multicolumn{6}{|l|}{ Age } \\
\hline $18-35$ & 43 & 37.39 & 72 & 62.61 & 1 \\
\hline $36-50$ & 56 & 44.44 & 70 & 55.56 & $1.34(0.799-2.244)$ \\
\hline $51-65$ & 28 & 37.84 & 46 & 62.16 & $1.02(0.557-1.862) *$ \\
\hline $66-93$ & 32 & 37.65 & 53 & 62.35 & $1.01(0.530-1.917)$ \\
\hline \multicolumn{6}{|l|}{ Residence } \\
\hline Dhaka & 37 & 37 & 63 & 63 & 1 \\
\hline Mymensing & 36 & 36 & 64 & 64 & $0.957(0.538-1.703)$ \\
\hline Sylhet & 45 & 45 & 55 & 55 & $1.39(0.791-2.452)$ \\
\hline Khulna & 41 & 41 & 59 & 59 & $1.18(0.669-2.089)$ \\
\hline \multicolumn{6}{|l|}{ Occupation } \\
\hline Housewife & 38 & 43.18 & 50 & 56.82 & $1.093(0.612-1.953)$ \\
\hline Farmer & 53 & 37.86 & 87 & 62.14 & $0.787(0.518-1.481)$ \\
\hline Private Job & 27 & 37.5 & 45 & 62.5 & $0.86(0.463-1.607)$ \\
\hline Unemployed & 41 & 41 & 59 & 59 & 1 \\
\hline \multicolumn{6}{|c|}{ Ever smoking cigarette } \\
\hline Yes & 91 & 52.6 & 82 & 47.4 & $2.59(1.718-3.917) * *$ \\
\hline No & 68 & 29.95 & 159 & 70.04 & 1 \\
\hline \multicolumn{6}{|c|}{ Current alcohol consumption } \\
\hline Yes & 2 & 20 & 8 & 80 & $0.37(0.077-1.770)$ \\
\hline No & 157 & 40.26 & 233 & 59.74 & 1 \\
\hline \multicolumn{6}{|c|}{ Fruits consumption per week } \\
\hline Two or fewer & 131 & 40.18 & 195 & 59.82 & $4.03(1.163-13.959)$ \\
\hline Three to four & 25 & 34.25 & 48 & 65.75 & $3.125(0.839-11.632) *$ \\
\hline Five or more & 3 & 14.29 & 18 & 85.71 & 1 \\
\hline \multicolumn{6}{|c|}{ Vegetables consumption per week } \\
\hline Two or fewer & 27 & 57.45 & 20 & 42.55 & $2.76(1.468-5.190)$ \\
\hline Three to four & 43 & 52.44 & 39 & 47.56 & $2.25(1.364-3.725) * *$ \\
\hline Five or more & 89 & 32.84 & 182 & 67.16 & 1 \\
\hline \multicolumn{6}{|c|}{ Physical activity status } \\
\hline Active & 96 & 36.5 & 167 & 63.5 & 1 \\
\hline Inactive & 63 & 45.99 & 74 & 54.01 & $1.48(0.973-2.252) * *$ \\
\hline \multicolumn{6}{|c|}{ Nutritional Status } \\
\hline Underweight & 11 & 23.92 & 35 & 76.08 & $0.87(0.417-1.822)$ \\
\hline Normal Weight & 62 & 26.5 & 172 & 73.5 & 1 \\
\hline Overweight & 69 & 74.19 & 24 & 25.81 & $7.98(4.612-13.793) * *$ \\
\hline Obese & 17 & 62.96 & 10 & 37.04 & 4.72(2.049-10.851) \\
\hline \multicolumn{6}{|l|}{ Diabetes Mellitus } \\
\hline Yes & 23 & 58.97 & 16 & 41.02 & $2.38(1.213-4.659) *$ \\
\hline No & 136 & 37.67 & 225 & 62.33 & 1 \\
\hline
\end{tabular}

$* \mathrm{p}$ value $<0.05, * * \mathrm{p}$ value $<0.01$

After applying logistic regression analysis, a significant association between hypertension and respondent's age, smoking status, fruits consumption, vegetables consumption, physical activity, overweight and presence of diabetes were found. Respondent whose age between 51-65 years had 1.02 higher chance of hypertension than those age were between 18-35 years. Respondents who had smoking habit had 2.59 higher odds of having hypertension. Those who consume fruits three to four days per week had 3.125 higher chance of hypertension and those who consume vegetable three to four days per week had 2.25 higher chance of hypertension. Respondents who were physically inactive had 1.48 times higher chance of hypertension. Those who were 
overweight and had diabetes mellitus ad 7.98 and 2.38 times higher chance of having hypertension.

\section{Discussion}

Just like other developing countries, Bangladesh is going through a rapid demographic and epidemiological transition. Nutrition is the key ingredient in all such transitions, and plays a predominant role.This cross-sectional community based study identified a high prevalence of

hypertension in the study area was $39.75 \%$. The prevalence of hypertension considerably higher than what has been reported in previous study conducted in Bangladesh (Ahmed et al., 2014). In India The prevalence of hypertension was found to be $23.24 \%$ (Patil, Sahoo, Dhoble, Kherde \& Inamdar, 2017) and in Nepal the prevalence was 32.5\% (Dhungana, Pandey, Bista, Joshi \& Devkota, 2016).

Among the male the prevalence was $23.5 \%$ and the prevalence was $16.5 \%$ among female.Similarly, several studies came out with the higher prevalence of hypertension in men than (Dhungana, Pandey, Bista, Joshi \& Devkota, 2016; Singh, Sinha, Mani, Singh \& Pal, 2011; Gao et al., 2013; Dzudie et al., 2012). One of the possible explanations for this is woman consume less tobacco and they are more interested in health care services utilization and report their poor health when it is necessary and therefore they are more likely to have better health (Singh, Shankar \& Singh, 2017). But this findings are contradictory to other findings where they found that women had more chance of developing hypertension compared to men (Kiber et al., 2019; Demisse et al., 2017; Helelo, Gelaw \& Adane, 2014).

In this study it was found that as the age was advancing so did the prevalence of hypertension. Similar findings were reported by other studies. Those studies found that advancing age waspositively related to hypertension (Erem et al., 2019; Gao et al., 2013; Tabrizi, Sadeghi-Bazargani, Farahbakhsh, Nikniaz \& Nikniaz, 2016; Costa et al., 2007).

In this study it was found that hypertension was moreprevalent in tobacco users (OR: 2.59) as compared to nonusers. This findings was consistence with other study findings (Dhungana et al., 2016; Reddy \& Prabhu, 2005; SIngh et al., 2011). But there are several other studies with contradictory findings (Erem et al., 2019; Costa et al., 2007; Peltzer \& Phaswana-Mafuya, 2013). Smoking cigarettes is known to impair the action of insulin, and may result in insulin resistance and it may also cause high BP by increasing sympathetic activity (Kong et al., 2001).

In this study overweight and physical inactivity were found to be independent risk factors for developing hypertension. This finding was in line with previous reports from Uganda, India, Ethiopia and Nepal (Kiber et al., 2019; Awoke et al., 2012; Patil et al., 2017; Dhungana et al., 2016). Urbanization are associated with changes in dietary habits and sedentary lifestyle which lead to obesity and those are associated as contributing factors in the development of high blood pressure. Reducing overweight and obesity through proper nutrition and increased regular physical activity is the best way to prevent hypertension (Goodpaster et al., 2010).

Respondents who had diabetes were about 2.38 times more likely to have hypertension. This could be because of the fact that both diseases share common risk factors and/or because of both (diabetes and hypertension) diseases can be mutually exclusive (Awoke et al., 2012). This finding is in agreement with several other studies (Awoke et al., 2012; Shishani, Dajani \& Khader, 2013; Rodrigues \& Ferreti, 2010).

In this study it was found that those who consume less fruits and vegetables had higher chance of developing hypertension and the odds are 3.12 and 2.25 respectively. This study findings further strengthens the previous findings (Borgi, Muraki, Satija, Willett, Rimm \& Forman, 2016; Li, Li, Wang \& Zhang, 2016). That is because fruits and vegetable are high in vitamin $\mathrm{C}$, folic acid, potassium, magnesium and carotenoid which have suggested to lower BP through improving endothelial function. fruits and vegetable also contain high amount of dietary fiber that have impact on diet structure by reducing fat intake which has been shown to be significantly associated with increased risk of hypertension (Shouying et al., 2007).

\section{Conclusion and Recommendation}

From the results of this study, it can be said that the prevalence hypertension is high in Bangladesh. We found that men are at more risk of developing hypertension than female. We need programs to improve surveillance systems and implement community-based screening programs to detect hypertension as early as possible. Interventions like improving health literacy to increase the awareness, weight management, increased physical activity, reduction in tobacco consumption, increased fruits and vegetables consumption are the need of the hour and are therefore recommended. 


\section{Acknowledgement}

This paper and the research behind it would not have been possible without the extraordinary support of Khaleda Islam, Professor of Institute of Nutrition and Food Science, University of Dhaka, Bangladesh. Her experience, enthusiasm and extreme attention to every detail have been a motivation and kept our work on track. We would also like to thank Shaidaton Nisha, Omar Faruk, Jakaria Al Mamun for the assistance and encouragement to pursue to the study. We also wish to thank our family members for the unconditional love and support. Last but not the list, we thank Almighty for reasons too numerous to mention.

\section{Ethical Consideration}

This study was approved by Ethical Review Board of University of Dhaka. The researchers clarified the objective of this research and obtained informed consent from the respondents.

\section{Funding}

No funding to be mentioned.

\section{Competing Interest}

Authors declare to have no conflict of interest.

\section{References}

Erem, C., Hacihasanoglu, A., Kocak, M., Deger, O., \& Topbas, M. (2009). Prevalence of prehypertension and hypertension and associated risk factors among Turkish adults: Trabzon Hypertension Study. J Public Health (Bangkok), 31(1), 47-58. https://doi.org/10.1093/pubmed/fdn078

Abebe, S. M., Berhane, Y., Worku, A., \& Getachew, A. (2015). Prevalence and associated factors of hypertension: a crossectional community based study in Northwest Ethiopia. PLoS One, 10(4), e0125210. https://doi.org/10.1371/journal.pone.0125210

Mishra, C. P., \& Kumar, S. (2011). Risk factors of hypertension in a rural area of Varanasi. Indian J Prev Soc Med., 42(1), 101-11.

Ahmed, A., Rahman, M., Hasan, R., Shima, S. A., Faruquee, M. H., Islam, T, \& Haque, E. S. (2014). Hypertension and associated risk factors in some selected rural areas of Bangladesh. Int J Res Med Sci., 2(3), 925. https://doi.org/10.5455/2320-6012.ijrms20140816

Collaboration, A. P. C. S. (2003). Blood pressure indices and cardiovascular disease in the Asia Pacific region: a pooled analysis. Hypertension, 42(1), 69-75. https://doi.org/10.1161/01.HYP.0000075083.04415.4B

Giles, T. D., Materson, B. J., Cohn, J. N., \& Kostis, J. B. (2009). Definition and classification of hypertension: an update. J Clin Hypertens, 11(11), 611-4. https://doi.org/10.1111/j.1751-7176.2009.00179.x

Zhou, B., Bentham, J., Di Cesare, M., Bixby, H., Danaei, G., Cowan, M. J., ... Ezzati, M. (2017). Worldwide trends in blood pressure from 1975 to 2015: a pooled analysis of 1479 population-based measurement studies with 19.1 million participants. Lancet, 389(10064), 37-55. https://doi.org/10.1016/S0140-6736(16)31919-5

Gakidou, E., Afshin, A., Abajobir, A. A., Abate, K. H., Abbafati, C., Abbas, K. M., et al. (2016). Global, regional, and national comparative risk assessment of 84 behavioural, environmental and occupational, and metabolic risks or clusters of risks, 1990-2016: a systematic analysis for the Global Burden of Disease Study 2016. Lancet, 390(10100), 1345-422. https://doi.org/10.1016/S0140-6736(17)32366-8

Chockalingam, A., Campbell, N. R., \& Fodor, J. G. (2006). Worldwide epidemic of hypertension. Can J Cardiol, 22(7), 553-5. https://doi.org/10.1016/S0828-282X(06)70275-6

Kiber, M., Wube, M., Temesgen, H., Woyraw, W., Belay, Y. A. (2019). Prevalence of hypertension and its associated factors among adults in Debre Markos Town, Northwest Ethiopia: community based cross-sectional study. BMC Res Notes, 12(1), 406. https://doi.org/10.1186/s13104-019-4431-9

Kearney, P. M., Whelton, M., Reynolds, K., Whelton, P. K., \& He, J. (2004). Worldwide prevalence of hypertension: a systematic review. J Hypertens, 22(1), 11-9.

https://doi.org/10.1097/00004872-200401000-00003

Abegunde, D. O., Mathers, C. D., Adam, T., Ortegon, M., \& Strong, K. (2007). The burden and costs of chronic diseases in low-income and middle-income countries. Lancet, 370(9603), 1929-38.

https://doi.org/10.1016/S0140-6736(07)61696-1 
Organization WH, others. (2013). A global brief on hypertension: silent killer, global public health crisis: World Health Day 2013.

Islam, J. Y., Zaman, M. M., Haq, S. A., Ahmed, S., \& Al-Quadir, Z. (2018). Epidemiology of hypertension among Bangladeshi adults using the 2017 ACC/AHA hypertension clinical practice guidelines and joint National Committee 7 guidelines. J Hum Hypertens, 32(10), 668-80.

https://doi.org/10.1038/s41371-018-0087-5

STEPS WHO. (2002). A Framework-The WHO STEPwise approach to surveillance of noncommunicable diseases (STEPS). WHO.

Angaw, K., Dadi, A. F., \& Alene, K. A. (2015). Prevalence of hypertension among federal ministry civil servants in Addis Ababa, Ethiopia: a call for a workplace-screening program. BMC Cardiovasc Disord, 15(1), 76. https://doi.org/10.1186/s12872-015-0062-9

Awoke, A., Awoke, T., Alemu, S., Megabiaw, B. (2012). Prevalence and associated factors of hypertension among adults in Gondar, Northwest Ethiopia: a community based cross-sectional study. BMC Cardiovasc Disord, 12(1),113. https://doi.org/10.1186/1471-2261-12-113

Demisse, A. G., Greffie, E. S., Abebe, S. M., Bulti, A. B., Alemu, S., Abebe, B., \& Mesfin, N. (2017). High burden of hypertension across the age groups among residents of Gondar city in Ethiopia: a population based cross sectional study. BMC Public Health, 17(1), 647. https://doi.org/10.1186/s12889-017-4646-4

Who, E. C. (2004). Appropriate body-mass index for Asian populations and its implications for policy and intervention strategies. Lancet (London, England), 363(9403), 157. https://doi.org/10.1016/S0140-6736(03)15268-3

Roba, H. S., Beyene, A. S., Mengesha, M. M., \& Ayele, B. H. (2019). Prevalence of hypertension and associated factors in Dire Dawa city, Eastern Ethiopia: a community-based cross-sectional study. Int J Hypertens, 2019. https://doi.org/10.1155/2019/9878437

Patil, C. R., Sahoo, D. P., Dhoble, M., Kherde, A., \& Inamdar, A. (2017). Prevalence of hypertension and its associated risk factors in young adults attending a tertiary care institute of Nagpur: A cross sectional study. Int J Community Med Public Heal, 4, 3630-5. https://doi.org/10.18203/2394-6040.ijcmph20174223

Dhungana, R. R., Pandey, A. R., Bista, B., Joshi, S., \& Devkota, S. (2016). Prevalence and associated factors of hypertension: a community-based cross-sectional study in municipalities of Kathmandu, Nepal. Int $J$ Hypertens. https://doi.org/10.1155/2016/1656938

Singh, R., Sinha, R. K., Mani, C., Singh, R., \& Pal, R. (2011). Burden and vulnerability of hypertension in a rural population of Patna, Bihar, India. South East Asia J Public Heal., 1(1), 53-8. https://doi.org/10.3329/seajph.v1i1.13221

Gao, Y., Chen, G., Tian, H., Lin, L., Lu, J., Weng, J., ... Yang, W. (2013). Prevalence of hypertension in China: a cross-sectional study. PLoS One, 8(6), e65938. https://doi.org/10.1371/journal.pone.0065938

Dzudie, A., Kengne, A. P., Muna, W. F. T., Ba, H., Menanga, A., Kouam, C. K., ... Kingue, S. (2012). Prevalence, awareness, treatment and control of hypertension in a self-selected sub-Saharan African urban population: a cross-sectional study. BMJ Open, 2(4). https://doi.org/10.1136/bmjopen-2012-001217

Singh, S., Shankar, R., \& Singh, G. P. (2017). Prevalence and associated risk factors of hypertension: a cross-sectional study in urban Varanasi. Int J Hypertens. https://doi.org/10.1155/2017/5491838

Helelo, T. P., Gelaw, Y. A., \& Adane, A. A. (2014). Prevalence and associated factors of hypertension among adults in Durame Town, Southern Ethiopia. PLoS One, 9(11), e112790. https://doi.org/10.1371/journal.pone.0112790

Tabrizi, J. S., Sadeghi-Bazargani, H., Farahbakhsh, M., Nikniaz, L., \& Nikniaz, Z. (2016). Prevalence and associated factors of prehypertension and hypertension in Iranian population: the Lifestyle Promotion Project (LPP). PLoS One, 11(10), e0165264. https://doi.org/10.1371/journal.pone.0165264

Costa, J. S. D. da, Barcellos, F. C., Sclowitz, M. L., Sclowitz, I. K. T., Castanheira, M., Olinto, M. T. A., ... Fuchs, C. S. (2007). Hypertension prevalence and its associated risk factors in adults: a population-based study in Pelotas. Arq Bras Cardiol, 88(1), 59-65. https://doi.org/10.1590/S0066-782X2007000100010

Reddy, S. S., \& Prabhu, G. R. (2005). Prevalence and risk factors of hypertension in adults in an Urban Slum, Tirupati, AP. Indian J community Med., 30(3), 84. https://doi.org/10.4103/0970-0218.42855 
SIngh, R. B., Fedacko, J., Pella, D., Macejova, Z., Ghosh, S., De, A. K., ... Gupta, K. A. (2011). Prevalence and risk factors for prehypertension and hypertension in five Indian cities. Acta Cardiol., 66(1), 29-37. https://doi.org/10.1080/AC.66.1.2064964

Peltzer, K., \& Phaswana-Mafuya, N. (2013). Hypertension and associated factors in older adults in South Africa. Cardiovasc J Afr., 24(3), 66. https://doi.org/10.5830/CVJA-2013-002

Kong, C., Nimmo, L., Elatrozy, T., Anyaoku, V., Hughes, C., Robinson, S., \& Elkeles, R. S. (2001). Smoking is associated with increased hepatic lipase activity, insulin resistance, dyslipidaemia and early atherosclerosis in Type 2 diabetes. Atherosclerosis, 156(2), 373-8. https://doi.org/10.1016/S0021-9150(00)00664-X

Wamala, J. F., Karyabakabo, Z., Ndungutse, D., \& Guwatudde, D. (2009). Prevalence factors associated with hypertension in Rukungiri district, Uganda-a community-based study. Afr Health Sci., 9(3).

Goodpaster, B. H., DeLany, J. P., Otto, A. D., Kuller, L., Vockley, J., ... South-Paul, J. E. (2010). Effects of diet and physical activity interventions on weight loss and cardiometabolic risk factors in severely obese adults: a randomized trial. Jama, 304(16), 1795-802. https://doi.org/10.1001/jama.2010.1505

Shishani, K., Dajani, R., \& Khader, Y. (2013). Hypertension risk assessment in the largest ethnic groups in Jordan. J Immigr Minor Heal., 15(1), 43-8. https://doi.org/10.1007/s10903-011-9533-y

Rodrigues, B. A., \& Ferreti, B. A. (2010). Arterial hypertension in the elderly of Bridgetown, Barbados: prevalence and associated factors. J Aging Health. 22(5), 611-30. https://doi.org/10.1177/0898264310371123

Borgi, L., Muraki, I., Satija, A., Willett, W. C., Rimm, E. B., \& Forman, J. P. (2016). Fruit and vegetable consumption and the incidence of hypertension in three prospective cohort studies. Hypertension, 67(2), 288-93. https://doi.org/10.1161/HYPERTENSIONAHA.115.06497

Li, B., Li, F., Wang, L., \& Zhang, D. (2016). Fruit and vegetables consumption and risk of hypertension: a meta-analysis. J Clin Hypertens, 18(5), 468-76. https://doi.org/10.1111/jch.12777

Shouying, C., Zhimei, X. I., \& Qun, Z. (2007). Risk factors in rural residents with essential hypertension of different social economic levels. Chin J Hypertens, 15, 764-7.

\section{Copyrights}

Copyright for this article is retained by the author(s), with first publication rights granted to the journal.

This is an open-access article distributed under the terms and conditions of the Creative Commons Attribution license (http://creativecommons.org/licenses/by/4.0/). 